\title{
El calcio de la dieta disminuiría el riesgo de litiasis renal en mujeres mientras que los suplementos cálcicos lo incrementarian
}

Curhan G, Willett W, Speizer F et al. Comparison of Dietary Calcium with Supplemental Calcium and Other Nutrients as Factors Affecting the Risk for Kidney Stones in Women.

Ann Intern Med. 1997; 126: 497-504

\section{Objetivo}

Determinar la asociación entre el calcio de la dieta y el de suplementos con el riesgo de litiasis renal en mujeres.

Diseño

Estudio prospectivo de cohortes, con 12 años de seguimiento.

\section{Lugar}

11 estados de EE.UU.

\section{Participantes}

91.731 enfermeras de 30-55 años que contestaron cuestionarios periódicos desde 1980 hasta 1992.

\section{Evaluación de Factores de Riesgo}

Los cuestionarios completados en 1980, 1984, 1986 y 1990 incluían información sobre hábitos dietéticos, suplementos cálcicos simples o compuestos como multivitamínicos, estilo de vida e incidencia de nuevas enfermedades.

\section{Medición de Resultados Principales}

Las participantes se agruparon en categorías por quintilos según consumo nutricional de calcio. El resultado principal fue la incidencia de litiasis renal sintomática.
Se ajustó para variables como edad, consumo de alcohol, BMI, consumo de vitaminas, suplementos de calcio, calcio en la dieta, etc.

\section{Resultados Principales}

Se documentaron 864 nuevos casos de litiasis renal sintomática. El $86 \%$ de los cálculos contenían calcio. Un mayor consumo de calcio de la dieta estuvo fuertemente asociado a una disminución del riesgo de litiasis renal $(\mathrm{P}<$ 0.001). El RR entre mujeres del quintilo superior de consumo de calcio dietario comparado con las del quintilo inferior fue 0.65 (IC 95\%, 0.50 - 0.83). En cuanto al empleo de suplementos cálcicos el riesgo relativo de las consumidoras fue 1.20 (IC 95\%, 1.02 - 1.41). Otros factores dietarios asociados: sucrosa, 1.52 (IC 95\%, 1.18 - 1.96); sodio, 1.30 (IC 95\%, 1.05 a 1.62); líquidos, 0.61 (IC 95\%, 0.48 0.78 ); y potasio, 0.65 (IC 95\%, 0.51 - 0.84). El fósforo y magnesio no tuvieron asociación significativa con la incidencia de litiasis renal; sin embargo, la asociación con el consumo de calcio dietario se atenuaba cuando estos elementos eran incluidos en el modelo de análisis, lo que revelaría la relación de estos nutrientes, que tienen en común a los productos lácteos como su principal fuente en la dieta.

\section{Conclusiones}

El consumo de calcio de la dieta tiene relación inversa con el riesgo de litiasis renal sintomática en mujeres, mientras que los suplementos de calcio incrementan el riesgo. Otros factores presentes en los lácteos, fuente principal del calcio de la dieta, podrían ser también responsables del descenso del riesgo.

\section{Comentario}

Solía pensarse que una dieta rica en calcio aumentaba el riesgo de litiasis renal, especialmente de cálculos de oxalato cálcico. En un estudio realizado en hombres se halló que esta relación es en realidad inversa (1). Esto podría explicarse por la unión del calcio al oxalato en el tubo gastrointestinal con la subsecuente disminución de ìa absorción y excreción renal del oxalato. El oxalato urinario sería más relevante que el calcio urinario en la formación de cristales de oxalato cálcico(2). El uso de suplementos de calcio aumenta la excreción de calcio en orina y si los mismos no se ingieren con las comidas no se produce la disminución de absorción de oxalato. El efecto neto es el aumento del riesgo de formación de cálculos. Otros factores nutricionales que la disminuyen son el fósforo y los líquidos. La fuente principal de calcio y fósforo de la dieta es común (los lácteos) por lo que el efecto protector podría ser compartido.
El efecto de los suplementos puede explicarse por el hecho de que un porcentaje de las mujeres ( $24 \%$ ) los consumían fuera de las comidas. De hecho la absorción del calcio de suplementos disminuye si se ingiere con los alimentos por lo que las pacientes pudieron haber sido instruidas en este sentido. No obstante, es facilista buscar simples explicaciones fisiopatológicas para la influencia de los diversos nutrientes en la formación de cálculos renales, pues los alimentos contienen cientos de componentes en proporciones y combinaciones complejas que distan de ser simples sumatorias de los mismos. Aún así, parece claro que no debe aconsejarse restricción de alimentos ricos en calcio en pacientes con nefrolitiasis, y por otro lado el riesgo atribuible al consumo de suplementos disminuiría si los mismos se ingieren con las comidas. Sin embargo, teniendo en cuenta que la incidencia global de cólicos renales fue baja:
864 casos en casi 92000 pacientes $(<1 \%)$; que los mismos tienen poca morbimortalidad y que la calcioterapia es eficaz contra condiciones que producen elevada morbilidad (osteoporosis), deben considerarse cuidadosamente las recomendaciones en cuanto a la modalidad de administración de suplementos por el riesgo de disminuir su absorción y por lo tanto su utilidad.

Dr. Alejandro Regueiro S.P.M Sistemas de Protección Médica

Referencias

1. Curhan GC, Willett WC, Rimm EB y col. A prospective study of dietary calcium and other

nutrients and the risk of symptomatic kidney stones. N Engl J Med. 1993; 328:833-8.

2. Borsatti A. Calcium oxalate nephrolithiasis: defecftive oxalate transport.

Kidney Int. 1991; 39:1283-98. 